\title{
A IMPORTÂNCIA DA EDUCAÇÃO EM SAÚDE COMO FERRAMENTA A FAVOR DA VACINAÇÃO CONTRA O SARAMPO E O COMBATE AO MOVIMENTO ANTIVACINA E FAKE NEWS
}

\author{
Paula Christina Correia Gonçalves ${ }^{1}$ \\ Basílio Magno Francisco Rodrigues da Silva ${ }^{2}$ \\ Fabíola Vargas Apolinário ${ }^{3}$
}

RESUMO: A presente pesquisa tem como temática a importância da educação em saúde com o uso de tecnologia leve em saúde, em prol da promoção da vacinação contra o Sarampo visando o combate às Fake News. Por se tratar de uma doença grave e altamente contagiosa, a vacinação contra o sarampo deveria ser amplamente incentivada em todas as regiões do Brasil. No entanto, observa-se que integrantes do movimento antivacina utilizam de Fake News interferindo na adesão da vacinação em crianças, jovens e adultos. Esse trabalho objetiva-se que a educação em saúde pode ajudar na sensibilização à vacinação contra Sarampo e outras doenças altamente contagiosas. Mais especificamente, o trabalho tem como papel fundamental fornecer fontes seguras de informações sobre o tema (sites como Ministério da Saúde, Programa Nacional de Imunização - PNI), conscientização sobre a influência da vacinação e o aumento de doenças reemergentes, promovendo à adesão e atualização da caderneta vacinal - Vacina tríplice viral (Sarampo, Caxumba e Rubéola) e esclarecer sobre possíveis motivos que nutrem o movimento antivacina e Fake News. Tratase de uma revisão bibliográfica sistemática. Verificou-se que apesar da vacinação infantil ser de grande eficácia, parte da população não foram vacinados por falta de acesso e de informação necessária. Os estudos evidenciaram a queda da cobertura vacinal e que a propagação de informações falsas sobre os riscos sobre a imunização colaborou para a não adesão, ocasionando o retorno de doenças anteriormente erradicadas. Para combater tal situação a educação em saúde torna-se um instrumento essencial para a enfermagem reverter esse quadro, seja por meio de busca ativa, seguida de orientações, como por meio de palestras em meios escolares.

Palavras-chave: Sarampo. Movimento antivacina. Fake News. Educação em Saúde. Enfermeiro.

ABSTRACT: The theme of this research is the importance of health education with the use of light technology in health, in favor of promoting vaccination against Measles in order to combat Fake News. As it is a serious and highly contagious disease, measles vaccination should be widely encouraged in all regions of Brazil. However, it is observed that members of the anti-vaccination movement use Fake News, interfering with adherence to vaccination in children, young people and adults. This work aims that health education can

\footnotetext{
${ }^{1} G$ raduanda em enfermagem pelo Centro Universitário Redentor, Enfermagem, Itaperuna-RJ, paulachristinaio@gmail.com.

${ }_{2}^{2}$ Graduando pelo Centro Universitário Redentor, Enfermagem, Itaperuna-RJ, magnob988@gmail.com.

3 Docente de Enfermagem pelo Centro Universitário Redentor, Enfermagem, Itaperuna-RJ, fabiola.apolinario@uniredentor.edu.br.
} 
help raise awareness of vaccination against Measles and other highly contagious diseases. More specifically, the work has the fundamental role of providing reliable sources of information on the subject (sites such as the Ministry of Health, National Immunization Program - PNI), awareness of the influence of vaccination and the increase in re-emerging diseases, promoting adherence and updating from the vaccination booklet - MMR vaccine (Measles, Mumps and Rubella) and to clarify possible reasons that nourish the anti-vaccine movement and Fake News. This is a systematic literature review. It was found that despite childhood vaccination being highly effective, part of the population was not vaccinated due to lack of access and necessary information. The studies showed a drop in vaccine coverage and that the spread of false information about the risks of immunization contributed to nonadherence, causing the return of previously eradicated diseases. To combat this situation, health education becomes an essential tool for nursing to reverse this situation, either through active search, followed by guidance, or through lectures in school environments.

Keywords: Measles. Anti-vaccination movement. Fake News. Health Education. Nurse.

\section{INTRODUÇÃO}

O Sarampo é uma doença viral bastante contagiosa, transmitida através das vias aéreas e por meio de contato direto de evolução gradativa e se não for tratada precocemente, pode ocorrer uma piora significativa do quadro geral evoluindo para óbito tendo sua maior incidência na infância e na adolescência (PEREIRA; BRAGA; COSTA, 2019).

Segundo os dados da Organização Mundial da Saúde (OMS), houve um aumento de 300\% dos casos da doença nos últimos dois anos no período de 2018, tornando um fenômeno global o avanço do sarampo (ALMEIDA; GRANCHI, 202o), e por esse motivo, o certificado de erradicação do Sarampo, conquistado pelo Brasil em 2016, fornecido pela Organização Pan-Americana da Saúde, foi perdido. Dessa forma, houve uma necessidade de uma vigilância contínua para obter o controle da doença na época (PEREIRA; BRAGA; COSTA, 2019).

O Ministério da saúde (MS), disponibiliza a imunização para crianças e adolescentes contra a Hepatite B, Difteria e Tétano, Febre Amarela e a Tríplice Viral (Sarampo, Caxumba e Rubéola), além de várias outras doenças. O Brasil é um dos países que possui o maior número de vacinas ofertadas pela rede pública, sendo mais de 300 milhões de doces anualmente (VIEGAS et al., 2019).

O termo Fake News se tornou mais presente via internet no período de 2016 em diante, e vem se tornando cada mais popular durante os anos. As Fake News afetam vários assuntos importantes como política e a saúde pública, assim como notícias sobre as vacinas essenciais como as vacinas de Poliomielite, Tríplice viral, entre outras, nutrindo o movimento antivacina na população em geral a recusa contra a vacinação de seus filhos (SARAIVA; DE FARIA, 2019). 
Com o acesso da internet e por meios de redes sociais, como WhatsApp, Facebook, Twitter, disseminando Fake News tornam-se os maiores responsáveis pela queda de $70 \%$ a $75 \%$ na cobertura vacinal desde 2016 (BRANCO; MORGADO, 2019 apud ALMEIDA et al., 2021). Desse modo, o ministério da Saúde visou criar uma campanha contra Fake News e desmentir as notícias sobre a vacinação em seu site oficial. Essa campanha, tem como objetivo postagens e envio de mensagens em um número de telefone que foi divulgado, afim de combater as notícias falsas sobre a saúde e obter notícias verdadeiras (BRASIL, 2021).

$\mathrm{O}$ argumento utilizado como base para o advento do movimento antivacina surgiu quando uma pesquisa publicada em 1998 explicava que a vacina tríplice viral desencadeava o autismo nas crianças. Desse modo, o assunto foi surgindo com mais força e muitas pessoas recusavam a vacinar seus filhos por medo (DINIZ, 2017).

Existem grupos de antivacina no mundo todo, dentre eles até comunidades religiosas. A divulgação de informação falsa sobre a vacinação contra o Sarampo, que é a forma mais eficaz de prevenção e segura, influenciam pessoas a não serem vacinadas e a não vacinarem seus descendentes, aumentando o número de pessoas suscetíveis a terem a doença, desse modo, o ressurgimento da doença no ano de 2020 é ainda maior, com base no efeito de Fake News sobre a vacinação do Coronavírus (MEDEIROS, 2020).

Com base na a OMS, o Sarampo ainda possui o vírus circundante em vários Países, principalmente no Brasil. Houve mais de 85 mil óbitos em 2016, porém, com a imunização evitou mais de 20 milhões de morte entre os anos 2000 e 2016, por tanto, a vacina é eficaz contra o Sarampo (PEREIRA; BRAGA; COSTA, 2019).

Segundo a revista Crescer (2021), 320 casos de Sarampo foram confirmados no estado do Amapá no mês de maio deste ano. Em 2019, apenas dois casos foram confirmados. Dessa forma, acredita-se que a pandemia do Coronavírus está aumentando os casos de doenças que já foram erradicadas no Brasil.

A educação em saúde possui métodos onde os profissionais de saúde valorizam a prevenção e promoção de saúde por meio de estudos ocasionados em comunidade e na sociedade. OMS define a educação em saúde como um processo de conhecimento e de desenvolvimento, que auxilia a população a ter autonomia no cuidado e debate com profissionais e gestores, visando alcançar uma atenção em saúde de acordo com sua necessidade. Com base nisso, a educação em saúde, sugere intervir sobre notícias falsas, mais conhecido por Fake News buscando formas de conscientizar e construir conhecimentos necessários e verdadeiros e definindo estratégias para o combate do movimento antivacina (FALKENBERG et al., 2014). 
Com base nessas informações, deve-se enfatizar a educação em saúde como ferramenta para o combate do movimento antivacina e Fake News, utilizando de prevenções, informações verdadeiras com fontes seguras para a população (NEVES et al., 202I).

\section{MATERIAIS E MÉTODOS}

A presente pesquisa trata-se de um estudo de revisão bibliográfica sistemática acerca do cenário atual do Sarampo e o movimento antivacina. Tal abordagem é caracterizada como uma pesquisa bibliográfica sistemática, sendo adequada para descrever e analisar o desenvolvimento de um determinado assunto (CAVALCANTE \& OLIVEIRA, 2020).

As perguntas que nortearam o estudo foram: Qual a importância da sensibilização da vacinação nos tempos de hoje? Quais motivos nutrem o movimento antivacina e Fake News?

Para respondê-la foi realizada uma busca no banco de dados: Google acadêmico, Scientific Electronic Library (Scielo), revistas online e sites oficiais como Ministério da Saúde (MS), sendo selecionados artigos publicados nos últimos seis anos. A pesquisa foi realizada em fevereiro de 202I, por meio da utilização de palavras chaves: sarampo, movimento antivacina, fake news, educação em saúde e Enfermeiro. Como critérios de inclusão, foram os seguintes: texto completo disponível na língua portuguesa, publicados nos períodos de 2015 a 2021.

Ainda foram excluídos artigos que não se enquadravam no período selecionado e que não abordavam a temática de estudo. A busca resultou em 35 artigos, que após o uso dos critérios de inclusão e exclusão, obteve 20 publicações.

\section{RESULTADOS E DISCUSSÃO}

\section{3.r Queda da cobertura vacinal contra o Sarampo}

A vacinação infantil é uma das formas mais eficazes para a prevenção de doenças graves, porém, uma parcela da população não aderiu à vacinação por falta de acesso aos serviços de saúde e pela falta de informação quanto à importância da vacinação. A vacinação contra o Sarampo evitou cerca de 21,I milhões de mortes no ano 2000 a 2017, atualmente, o Sarampo é responsável por 44\% das I,7 milhões de mortes que poderiam ter sido evitadas por vacinas em crianças anualmente. A vacina contra o Sarampo é indicada aos 12 meses ou aos 15 meses de vida, combinada com as vacinas de Caxumba e Rubéola, mais conhecida como a vacina Tríplice Viral (PERSON; PUGA; ATALLAH, 2019).

Segundo o Programa Nacional de Imunização (PNI) indivíduos de 30 anos a 59 anos precisam apresentar or(uma) dose da Tríplice Viral e profissionais de saúde independentemente da 
idade para serem considerados vacinados necessitam de 02 (doses). Em ambos os casos que divergem do esquema vacinal supracitado deve-se promover a atualização das doses. (BRASIL, 202I).

O Sarampo possui fases distintas, sendo elas a de incubação, prodrômica e exantemática. A transmissão da doença pode ser feita possivelmente em cinco dias antes ou quatro dias depois do surgimento do exantema. A fase de incubação dura em torno de io a 14 dias e é geralmente assintomática. A fase prodrômica dura cerca de 2 a 8 dias, com a presença de sintomas como febre, mal-estar, tosse, coriza e conjuntivite. Em alguns casos, Sinais de Koplik, que corresponde a pequenos pontos brancos na pele, podem aparecer em 24 a 48 horas antes do surgimento do exantema (XAVIER et al., 2019).

Segundo Wanderley et al (2021) de janeiro do ano de 2015 a Dezembro de 2019 ocorreu o aumento de internações decorrentes do sarampo, aproximadamente 1.875 indivíduos precisaram ser hospitalizados. A tabela um apresenta a distribuição dos casos.

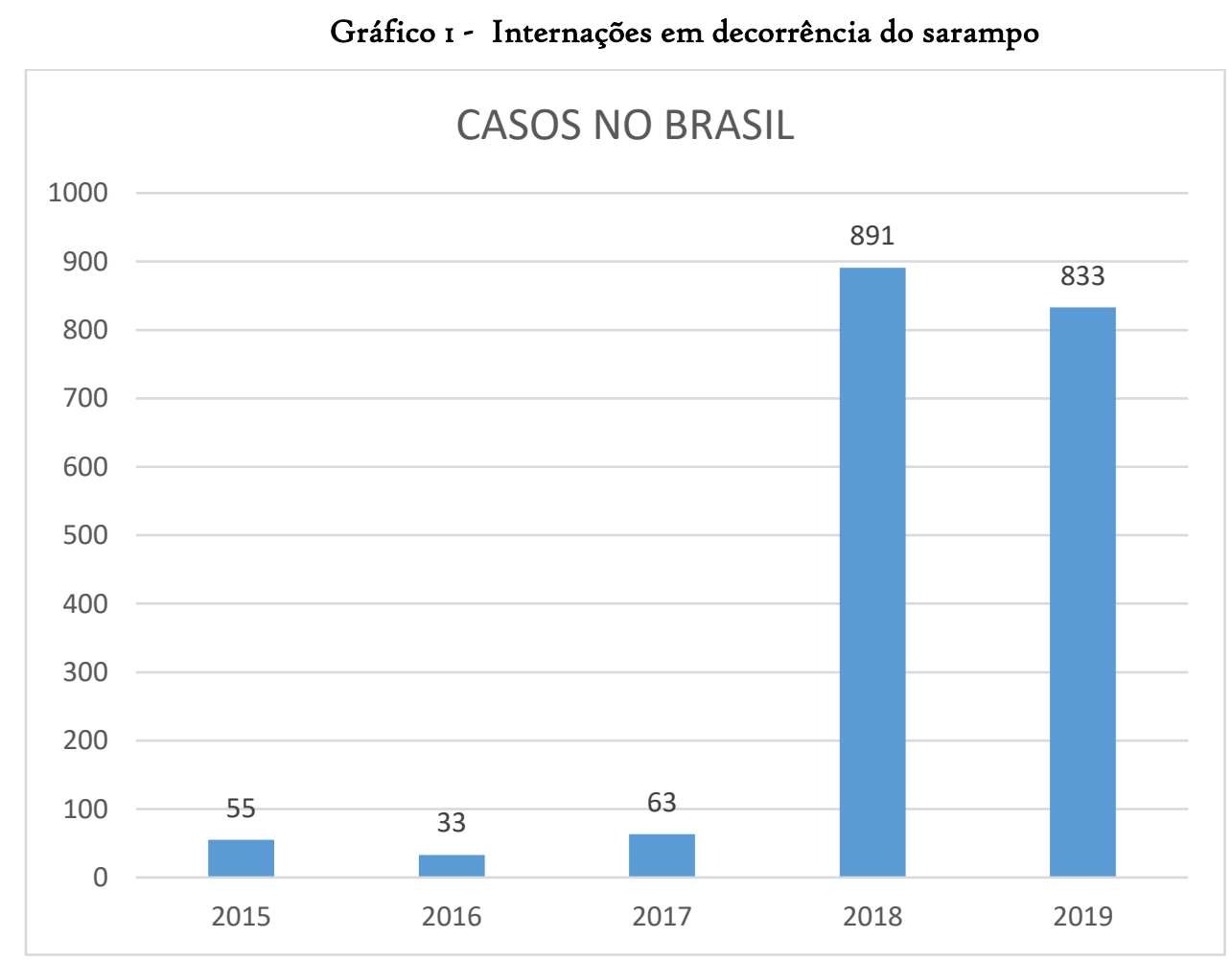

Fonte: Wanderley et al (2021) 


\subsection{Fake News e Movimento Antivacina}

Segundo Pinto Júnior (2019), o movimento antivacina tem ganhado força no mundo inteiro, apesar dos avanços obtidos com as vacinas na redução drástica da incidência das doenças contagiosas. A ignorância e a facilidade de disseminação de informações falsas por meios tecnológicos e elevação de poderes políticos vem sendo um dos principais fatores do crescimento do movimento.

Crenças ligadas a riscos da vacinação interfere nas modificações epidemiológicas nas famílias de classe média de países industrializados. Estas crenças crescem ainda mais por conta das redes sociais, blogs, indivíduos com alta influência, políticos, sendo passadas informações falsas sobre os riscos da vacinação, criando sérios problemas na saúde dessas famílias (VASCONCELLOS-SILVA; CASTIEL; GRIEP, 2015).

Foi realizada uma pesquisa recente que identificou a internet como uma barreira de informação sobre a importância da vacinação. Mobilizações online e movimentos antivacinais foram um dos principais responsáveis pela redução de confiança em relação às vacinas pela população. $O$ acesso à internet e nas mídias sociais, que foram revolucionais para o acesso de informações, possui também o crescente número de informações falsas que tornou um sério problema de saúde no Brasil. Recentemente, a divulgação de informações falsas pelas mídias sociais ganhou um termo próprio, 2943 chamado de Fake News. Com essa definição, entende-se que o nome Fake News são artigos ou notícias intencionalmente falsas, visando enganar os leitores para fins lucrativos ou políticos. A maioria das Fakes News que englobam o assunto sobre saúde, envolve a vacinação (FRUGOLI et al., 2021).

\section{Quadro I - Relação fake news e suas consequências}

\begin{tabular}{|c|c|c|c|}
\hline Autor/Autores & Título de Artigo & Variáveis & Afirmações \\
\hline $\begin{array}{c}\text { Rodrigues } \text { et al. } \\
\text { (2020) }\end{array}$ & $\begin{array}{c}\text { Atualizações } \\
\text { sobre a } \\
\text { imunização } \\
\text { contra o sarampo } \\
\text { no Brasil: uma } \\
\text { revisão } \\
\text { sistemática. }\end{array}$ & $\begin{array}{c}\text { Distorção e divulgação } \\
\text { de informações falsas } \\
\text { alegando embasamento } \\
\text { científico. As vacinas } \\
\text { tríplice viral, adjuvantes } \\
\text { e o conservante } \\
\text { timerosal são os } \\
\text { principais responsáveis } \\
\text { pela ocorrência de } \\
\text { síndrome de espectro } \\
\text { autista em crianças. }\end{array}$ & $\begin{array}{c}\text { "Por conta do movimento } \\
\text { antivacionas, no ano de 2or6, } \\
\text { ocorreu significativo declínio } \\
\text { na imunização de crianças e } \\
\text { adolescentes impulsionadas } \\
\text { pela Fake News." }\end{array}$ \\
\hline $\begin{array}{c}\text { Machado et al., } \\
\text { (2020) }\end{array}$ & $\begin{array}{c}\text { Recusa vacinal } \\
\text { impacto no } \\
\text { ressurgimento de }\end{array}$ & $\begin{array}{c}\text { motivadas pela religião, } \\
\text { opinião de terceiros e }\end{array}$ & $\begin{array}{c}\text { "A partir do movimento } \\
\text { antivacinas, ocorreu aumento } \\
\text { nos casos de doenças virais. As } \\
\text { falsas notícias impulsionam o }\end{array}$ \\
\hline
\end{tabular}




\begin{tabular}{|c|c|c|c|}
\hline & $\begin{array}{l}\text { doenças } \\
\text { erradicadas. }\end{array}$ & $\begin{array}{l}\text { desconfiança da } \\
\text { indústria da vacina. }\end{array}$ & $\begin{array}{c}\text { retorno de doenças já } \\
\text { erradicadas.” }\end{array}$ \\
\hline $\begin{array}{l}\text { Frugoli et al., } \\
\qquad(202 \mathrm{I})\end{array}$ & $\begin{array}{l}\text { Fake news sobre } \\
\text { vacinas: uma } \\
\text { análise sob o } \\
\text { modelo dos }{ }_{3} \mathrm{Cs} \\
\text { da Organização } \\
\text { Mundial da } \\
\text { Saúde. }\end{array}$ & $\begin{array}{c}\text { Fake news e movimento } \\
\text { antivacina }\end{array}$ & $\begin{array}{l}\text { "Mobilizações online e } \\
\text { movimentos antivacinais } \\
\text { foram um dos principais } \\
\text { responsáveis pela redução de } \\
\text { confiança em relação às } \\
\text { vacinas pela população. O } \\
\text { acesso à internet e nas mídias } \\
\text { sociais, que foram } \\
\text { revolucionais para o acesso de } \\
\text { informações, possui também o } \\
\text { crescente número de } \\
\text { informações falsas que tornou } \\
\text { um sério problema de saúde } \\
\text { no Brasil." }\end{array}$ \\
\hline
\end{tabular}

Desde o surgimento dos movimentos antivacina, as epidemias erradicadas pela cobertura vacinal perderam a efetividade e dispersão das manipulações das informações, como o caso ocorrido em São Paulo no ano de 2008. Nesse período, ocorreu a falsa notícia do retorno da epidemia de febre amarela, responsável por agitação promovida pela população evidenciada pela alta procura pela vacina contra a febre amarela, resultou nas várias doses repetidas, aumentando em cinco vezes o número de doses aplicadas por pessoa, sendo necessárias apenas uma, o que desencadeou vários efeitos colaterais e quatro óbitos na época (HENRIQUE, 2018).

\subsection{Educação em Saúde Interligado a Vacinação}

A Educação em saúde tem como finalidade de processo educacional, visando a troca de informação, partindo do profissional de saúde para a população. Essa troca de informação pode ser fornecida com ferramentas tecnológicas ou recursos simples, dessa forma, o enfermeiro pode utilizar de diversos meios para levar o conhecimento para as pessoas, realizando a promoção e prevenção da saúde (SALCI et al., 2013 apud GONÇALVES et al., 2020).

Para reforçar a saúde nas escolas, contribuindo com a promoção e atenção à saúde, na prevenção de riscos e agravos e na vulnerabilidade que as crianças e adolescentes na rede pública de ensino, foi criado o Programa Saúde na Escola (PSE), com o intuito de integrar e articular de modo permanente os segmentos da saúde dos estudantes, sendo uma das várias ações previstas a situação vacinal e de doenças. (VIEGAS et al., 2019). 
Segundo Viegas et al. (2019), foram feitas atividades de educação em saúde que foram norteadas pelo modelo de intervenção designado de "Educação para a Saúde Crítica", essa intervenção decorreu da Declaração de Alma-Ata. Nesse estudo teve como objetivo de desenvolver a autonomia e a responsabilidade para adotar estilos saudáveis de vida.

A educação em saúde engloba diversos aspectos e o enfermeiro pode estar orientando a população sobre a vacinação, realizando visitas no âmbito domiciliar quando o indivíduo não pode comparecer a unidade, devendo verificar o cartão de vacinação, orientando quanto a sua atualização (MOSCÔsO et al.,2021).

Um relato de experiência de alunos da graduação em enfermagem demonstrou que os profissionais podem intervir para a prevenção do sarampo em escolas, por meio de cartazes que abordassem sobre a doença e seus principais aspectos. Após a apresentação dos cartazes de forma clara e objetiva foi possível verificar que os indivíduos aderiram as informações que lhes foram passadas, colaborando para a disseminação de conhecimentos e adesão a imunização (GOMES et al.,2020).

Quadro 2 - Relação fake news e intervenções de combate

\begin{tabular}{|c|c|c|c|}
\hline Autor/Autores & Título de Artigo & Variáveis & Afirmações \\
\hline $\begin{array}{l}\text { Almeida et al., } \\
(2020)\end{array}$ & 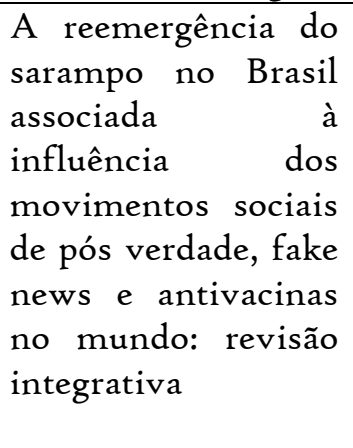 & $\begin{array}{l}\text { Fake news } \\
\text { popularizadas através } \\
\text { de redes sociais e } \\
\text { aplicativos de troca de } \\
\text { mensagens como } \\
\text { WhatsApp, Twitter e } \\
\text { Facebook }\end{array}$ & $\begin{array}{l}\text { "Com a queda da procura pela } \\
\text { vacina contra o sarampo, } \\
\text { compreendida entre pessoas } \\
\text { da faixa etária dos I3-I8 anos. } \\
\text { Diante disso, o Ministério da } \\
\text { Saúde passou a democratizar } \\
\text { a informação, levando a } \\
\text { população a compreender que } \\
\text { informações falsas causam } \\
\text { danos severos à saúde" }\end{array}$ \\
\hline $\begin{array}{l}\text { Megiani; Lopes; } \\
\text { Lázaro (202I). }\end{array}$ & $\begin{array}{l}\text { Retorno do sarampo: } \\
\text { entre a fake news e a } \\
\text { Saúde Pública. }\end{array}$ & $\begin{array}{l}\text { Andrew Wakefiel } \\
\text { atribui o autismo a } \\
\text { imunização pela } \\
\text { tríplice viral. }\end{array}$ & $\begin{array}{l}\text { "Para desmentir a falsa } \\
\text { informação espalhada, foram } \\
\text { realizados estudos que } \\
\text { revelaram não haver } \\
\text { nenhuma relação do autismo } \\
\text { com a tríplice viral, mas a } \\
\text { falta de imunização pode } \\
\text { ocasionar riscos a população." }\end{array}$ \\
\hline $\begin{array}{l}\text { Salci et al., (2013) } \\
\text { apud Gonçalves } \\
\text { et al., (2020) }\end{array}$ & $\begin{array}{l}\text { Educação em saúde } \\
\text { como estratégia de } \\
\text { prevenção ra e } \\
\text { promoção da saúde } \\
\text { de uma unidade } \\
\text { básica de saúde. }\end{array}$ & $\begin{array}{l}\text { Fake news } \\
\text { popularizadas através } \\
\text { de redes sociais e } \\
\text { aplicativos de troca de } \\
\text { mensagens como } \\
\text { WhatsApp, Twitter e }\end{array}$ & $\begin{array}{l}\text { "Contribuindo com a } \\
\text { promoção e atenção à saúde, } \\
\text { na prevenção de riscos e } \\
\text { agravos e na vulnerabilidade } \\
\text { que as crianças e adolescentes } \\
\text { na rede pública de ensino, foi }\end{array}$ \\
\hline
\end{tabular}




\begin{tabular}{|l|lr|l|l|}
\hline & & $\begin{array}{l}\text { Facebook direcionadas } \\
\text { ao público infanto- } \\
\text { juvenil em idade } \\
\text { escolar }\end{array}$ & $\begin{array}{l}\text { criado o Programa Saúde na } \\
\text { Escola (PSE)," }\end{array}$ \\
\hline $\begin{array}{l}\text { Moscôso } \\
\text { et al.,(202I) }\end{array}$ & $\begin{array}{l}\text { Intervenções } \\
\text { enfermagem } \\
\text { prevenção } \\
\text { caxumba }\end{array}$ & $\begin{array}{r}\text { na } \\
\text { na }\end{array}$ & $\begin{array}{l}\text { Fake news e pacientes } \\
\text { com baixa mobilidade }\end{array}$ & $\begin{array}{l}\text { "A educação em saúde } \\
\text { engloba diversos aspectos e o } \\
\text { enfermeiro pode estar } \\
\text { orientando a população sobre } \\
\text { a vacinação, realizando } \\
\text { visitas no âmbito domiciliar } \\
\text { quando o indivíduo não pode } \\
\text { comparecer a unidade, } \\
\text { devendo verificar o cartão de } \\
\text { vacinação, orientando quanto } \\
\text { a sua atualização." }\end{array}$ \\
\hline
\end{tabular}

\section{${ }_{4}$ CONCLUSÃO}

É perceptível que a educação em saúde é uma importante ferramenta para que a população possa compreender sobre a imunização contra o sarampo, visto o aumento de casos em razão das Fakes News e movimentos antivacina.

Os estudos evidenciaram a queda da cobertura vacinal e que a propagação de informações falsas sobre os riscos sobre a imunização colaborou para a não adesão, ocasionando o retorno de doenças anteriormente erradicadas. Para combater tal situação a educação em saúde torna-se uma instrumento essencial para a enfermagem reverter esse quadro, seja por meio de busca ativa, seguida de orientações, como por meio de palestras em meios escolares, utilizando tecnologias educativas em geral.

\section{REFERÊNCIAS BIBLIOGRÁFICAS}

ALMEIDA, Cristina; GRANCHI, Giulia. Sarampo: sintomas, transmissão, como prevenir e tratar a doença. Viva bem uol. São Paulo. Disponível em: https://www.uol.com.br/vivabem/noticias/redacao/2019/o7/24/sarampo-sintomas-transmissaoe-duvidas-sobre-o-surto-e-a-vacina.htm>. Acesso em: 05. Mai. 2021.

ALMEIDA, H. da S. et al. A reemergência do sarampo no Brasil associada à influência dos movimentos sociais de pós verdade, fake news e antivacinas no mundo: revisão integrativa. Revista Eletrônica Acervo Saúde, v. 13, n. 3, p. 6226. Disponível em: 〈https://acervomais.com.br/index.php/saude/article/view/6226/43II〉. Acesso em: 05. Mai. 202I.

BRASIL. Ministério da Saúde. Saúde sem Fake News. Brasília. Disponível em: <https://antigo.saude.gov.br/fakenews/〉. Acesso em: 05. Mai. 2021. 
BRASIL. Ministério da Saúde. Guia Prático de Imunizações para trabalhadores da sala de vacinação. Brasília. Disponível em: <saude.go.gov.br/files/imunizacao/Guia.Pratico.Imunizacao.ıED.202r.pdf> Acesso em: I8. Nov. 2021

CAVAlCANTE, Lívia Teixeira Canuto; OlIVEIRA, Adélia Augusta Souto de. MÉTODOS DE REVISÃO BIBLIOGRÁFICA NOS ESTUDOS CIENTÍfICOS. Psicologia em Revista, Belo Horizonte, v. 26, n. I, p. 83-102, 2020. Disponível em: $\langle$ http://periodicos.pucminas.br/index.php/psicologiaemrevista/article/view/12005/18070〉. Acesso em: 18. Nov. 2021.

DINIZ, Thais Carvalho. Movimento antivacina: como surgiu e quais consequências ele pode trazer?. Universa, São Paulo, 2017. Disponível em: https://www.uol.com.br/universa/noticias/redacao/2017/12/o5/o-que-o-movimento-antivacinapode-causar.htm>. Acesso em: 06. Mai. 202I.

FALKENBERG, Mirian Benites et al. Educação em saúde e educação na saúde: conceitos e implicações para a saúde coletiva. Ciência \& Saúde Coletiva, v. I9, p. 847-852, 2014. Disponível em: $<$ https://www.scielosp.org/article/csc/2014.vign3/847-852/pt/ 〉. Acesso em: Io. Nov. 2021.

FRUGOLI, Alice Gomes et al. Fake news sobre vacinas: uma análise sob o modelo dos ${ }_{3} \mathrm{Cs}$ da Organização Mundial da Saúde. Revista da Escola de Enfermagem da USP, v. 55, 2021. Disponível em: 〈https://www.scielo.br/j/reeusp/a/G6LTwYzSPqcGS6D7xw47bpL/〉. Acesso em: io. Nov. 2021.

GOMES, Yury et al. Educação em saúde em um centro de saúde escola acerca da prevenção ao sarampo: um relato de experiência. Revista Eletrônica Acervo Saúde, v. 12, n. 9, p. e4166-e4166, 2020. Disponível em: $\langle$ https://acervomais.com.br/index.php/saude/article/view/4166/2596>. Acesso em: Io. Nov. 2021.

GONÇALVES, Romário de Sousa et al. Educação em saúde como estratégia de prevenção e promoção da saúde de uma unidade básica de saúde. Brazilian Journal of Health Review, v. 3, n. 3, p. $\quad 5811-5817,2020 . \quad$ Disponível em: 〈https://www.brazilianjournals.com/index.php/BJHR/article/view/ıin22〉. Acesso em: ı. Nov. 202I

MACHADO, Luis Felipe Barbosa et al. Recusa vacinal e o impacto no ressurgimento de doenças erradicadas. Brazilian Journal of Surgery and Clinical Research - BJSCR. Vol.32, n.I, p.I2-16 (Set Nov 2020). Disponível em: 〈https://www.mastereditora.com.br/periodico/20200907_164040.pdf〉. Acesso em: io. Nov. 2021.

MEDEIROS, Eduardo Alexandrino Servolo. Entendendo o ressurgimento e o controle do sarampo no Brasil. Acta Paulista de Enfermagem, v. 33, 2020. Disponível em: 
〈https://www.scielo.br/j/ape/a/MmLDTx4fkq6hJy4Nzzs3vDgx/?lang=pt〉. Acesso em: io. Nov. 2021.

MEGIANI, Isabela Nishimura; LOPES, Isabela Ressutte; LÁZARO, Camila Aline. Retorno do sarampo: entre a fake news e a Saúde Pública. Research, Society and Development, v. io, n. 2, e23510212452, P.I-I8, 2021. Disponível em: <https://www.researchgate.net/publication/349354545_Retorno_do_sarampo_entre_a_fake_news_e_ a_Saude_Publica>. Acesso em: ro. Nov. 2021.

MOURA, Ana Débora Assis et al. Estratégias e resultados da vacinação no enfrentamento da epidemia de sarampo no Estado do Ceará, 2013-2015. Epidemiologia e serviços de saúde, v. 27, 2018. Disponível

em: 〈https://www.scielo.br/j/ress/a/7nR8MdMkqYBnVSt6CrkQLfg/abstract/?lang=pt . Acesso em: II. Nov. 202I.

MOSCÔSO, Lilian et al. INTERVENÇÕES DE ENFERMAGEM NA PREVENÇÃO DA CAXUMBA. REVISTA ACADÊMICA FACOTTUR-RAF, v. 2, n. I, p. 69-78, 2021. Disponível em: $\langle$ http://raf.emnuvens.com.br/raf/article/view/38/16>. Acesso em: ir. Nov. 2021.

NEVES, Vanusa Nascimento Sabino et al. Utilização de lives como ferramenta de educação em saúde durante a pandemia pela COVID-19. Educação \& Sociedade, v. 42, 2021. Disponível em: 〈https://www.scielo.br/j/es/a/yVCyYWbQPrZNYdBgsYtWwHt/〉. Acesso em: II. Nov. 202I.

PEREIRA, João Pedro Campos; BRAGA, Gabriele Maria; COSTA, Gabriela Araújo. Negligência à vacinação: o retorno do sarampo ao Brasil. e-Scientia, v. I2, n. I, p. I-5, 2019. Disponível em: $\langle$ https://revistas.unibh.br/dcbas/article/view/2826/pdf〉. Acesso em: 12. Nov. 2021

PERSON, Osmar Clayton; PUGA, Maria Eduarda dos Santos; ATALLAH, Álvaro Nagib. Riscos, benefícios e argumentos para vacinação contra o sarampo: uma síntese de evidências. Diagn Tratamento, v. $24, \quad$ n. 3 , p. I02-105, 2019. Disponível em: 〈https://docs.bvsalud.org/biblioref/2019/12/1026696/rdt_v24n3_102-105.pdf〉. Acesso em: II. Nov. 2021.

PINTO JÚNIOR, Vitor Laerte et al. Antivacinação, um movimento com várias faces e consequências. Cadernos Ibero-Americanos de Direito Sanitário, v. 8, n. 2, p. II6-I22, 2019. Disponível em: 〈https://www.cadernos.prodisa.fiocruz.br/index.php/cadernos/article/view/542/595〉. Acesso em: 17. Mai. 2021.

REVISTA CRESCER. Amapá confirma morte de dois bebês por sarampo. Revista Crescer. Editora Globo, 202I. Disponível em: <https://revistacrescer.globo.com/Saude/noticia/2021/o5/amapaconfirma-morte-de-dois-bebes-por-sarampo.html>. Acesso em: 17. Mai. 2021. 
RODRIGUES, Bruna Larissa Pinto et al. Atualizações sobre a imunização contra o sarampo no Brasil: uma revisão sistemática. Revista Eletrônica Acervo Saúde, Vol.Sup.n.55, p.I-9, 2020. Disponível em: 〈https://acervomais.com.br/index.php/saude/article/view/3919/2381 >. Acesso em: II. Nov. 2021

SARAIVA, L. J. C. da; DE FARIA, Joana Frantz. A Ciência e a Mídia: A propagação de Fake News e sua relação com o movimento antivacina no Brasil. In: anais do $4_{2}{ }^{\circ}$ Congresso Brasileiro de Ciências da Computação. Belém, PA. Recuperado de http://portalintercom.org.br/anais/nacional2or9/resumos/Ri4-1653-I.pdf. 2019. Disponível em: $\langle$ https://portalintercom.org.br/anais/nacional2019/resumos/Ri4-1653-I.pdf $\rangle$. Acesso em: ir. Nov. 2021.

VASCONCELlOS-SILVA, Paulo Roberto; CASTIEL, Luis David; GRIEP, Rosane Härter. A sociedade de risco midiatizada, o movimento antivacinação e o risco do autismo. Ciência \& saúde coletiva, v. 20, p. 607-616, 2015. Disponível em: 〈https://www.scielo.br/j/csc/a/dsShVKNj7bJkJWjBWmKbXTv/?format=pdf\&lang=pt . Acesso em: 12. Nov. 2021.

VIEGAS, Selma Maria da Fonseca et al. A vacinação e o saber do adolescente: educação em saúde e ações para a imunoprevenção. Ciência \& Saúde Coletiva, v. 24, p. 351-36o, 2019. Disponível em: 〈https://www.scielo.br/j/csc/a/5ZSS6fQcdC9w3pcSvRpvgGD/abstract/?lang=pt〉. Acesso em: 17. Mai. 2021.

XAVIER, Analucia R. et al. Diagnóstico clínico, laboratorial e profilático do sarampo no Brasil. Jornal Brasileiro de Patologia e Medicina Laboratorial, v. 55, n. 4, p. 390-40I, 2019. Disponível em: 〈https://www.scielo.br/j/jbpml/a/d4HfzvcFGZ 75 SYHL9ZZhkkt/?lang=pt〉. Acesso em: i7. Mai. 202I.

WANDERLEY, Renata Lins et al. Perfil epidemiológico das ocorrências de sarampo no Brasil durante os últimos 5 anos. Brazilian Journal of Development, v. 7, n. I, p. 3784-3794, 2021. Disponível em: 〈https://www.brazilianjournals.com/index.php/BRJD/article/view/22954/18429>. Acesso em: 12. Nov. 2021. 